\title{
Implementing Model Semantics \\ and a (MB)SE Ontology in Civil \\ Engineering and Construction Sector
}

\author{
Henrik Balslev
}

\begin{abstract}
In the period from 2010 to 2015, the Danish Building Construction Sector has implemented basic parts of Systems Engineering as the new 'common language' in the building construction sector. The project is anchored in the public and EU supported "cuneco project". www.cuneco.dk develops the common basis for digitalized cooperation in construction, operation and maintenance to increase efficiency and productivity through enhanced exchange of information. To allow maximum simplicity yet unlimited flexibility, systems and their constituents are first classified and then identified individually to be used consistently over the lifecycle of the component, suitable for IT support. The system-of-systems principle is a fundamental approach to achieve unambiguous identification based on the Reference Designation System principles as defined in ISO/IEC 81346 standard series, which originally is designed for modelling and labelling of any kind of industrial plant. Currently, the Danish result is used to update some parts of the 81346 standard series, and thereby introducing Systems Engineering to the building construction sector.
\end{abstract}

H. Balslev (ه)

Systems Engineering A/S, Østerbrogade 56A, DK-2100 Copenhagen Ø, Denmark

e-mail: hb@syseng.dk

URL: http://www.syseng.dk; http://www.81346.com

(C) Springer International Publishing Switzerland 2016

G. Auvray et al. (eds.), Complex Systems Design \& Management,

DOI 10.1007/978-3-319-26109-6_22 